\title{
Abordagem laboratorial no diagnóstico da alergia alimentar
}

\author{
Laboratorial approach in the diagnosis of food allergy
}

\begin{abstract}
Renata Rodrigues Cocco ${ }^{1}$, Inês Cristina Camelo-Nunes², Antonio Carlos Pastorino ${ }^{3}$, Luciana Silva ${ }^{4}$, Roseli Oselka S. Sarni ${ }^{5}$, Nelson Augusto Rosário Filho ${ }^{6}$, Dirceu Solé7
\end{abstract}

\section{RESUMO}

Objetivo: Revisar os exames laboratoriais disponíveis utilizados no diagnóstico da alergia alimentar mediada ou não por IgE.

Fontes de dados: Artigos publicados em base de dados PubMed e Embase (língua inglesa e portuguesa) nos últimos dez anos. As palavras-chave utilizadas como fonte de busca foram "alergia alimentar", "diagnóstico" e "laboratório”, isolados e/ou associados.

Síntese dos dados: A abordagem diagnóstica das reações alérgicas a alimentos inclui história clínica completa, estudos laboratoriais, dietas de eliminação e desencadeamentos cegos com alimentos. Recentemente, a medida quantitativa de anticorpos IgE específicos a alimentos tem mostrado ser mais preditiva de alergia alimentar sintomática mediada por IgE. Níveis séricos de IgE específica a alimento que excedam os valores diagnósticos indicam que o paciente tem chance maior que $95 \%$ de apresentar uma reação alérgica se ingerir o alimento em questão. Estes "valores de decisão" foram definidos para alguns alimentos e resultados inconsistentes são obtidos ao se estudar diferentes populações. Os desencadeamentos com alimento, especialmente o duplo-cego controlado por placebo (DADCCP), representa a maneira mais confiável de estabelecer ou descartar o diagnóstico de hipersensibilidade alimentar.

Conclusões: Número crescente de aquisições tem melhorado ovalor preditivo de alguns testes laboratoriais empregados no diagnóstico de alergias alimentares. Entretanto, até hoje, não há teste in vitro ou in vivo que mostre correlação completa com a clínica da alergia alimentar. O DADCCP continua sendo o padrão-ouro no diagnóstico definitivo de alergia alimentar específica. São necessárias, urgentemente, novas abordagens diagnósticas válidadas em pacientes com alergia alimentar confirmada por DADCCP positivo.

Palavras-chave: hipersensibilidade alimentar; imunoglubulina E; hipersensibilidade mediada por IgE; alérgenos; desencadeamento.

${ }^{1}$ Mestre em Pediatria, médico da Disciplina de Alergia, Imunologia Clínica e Reumatologia do Departamento de Pediatria da Escola Paulista de Medicina da Universidade Federal de São Paulo (Unifesp-EPM)

²Doutor em Medicina, médico da Disciplina de Alergia, Imunologia Clínica e Reumatologia do Departamento de Pediatria da Unifesp-EPM

${ }^{3}$ Doutor em Medicina, médico assistente do Instituto da Criança do Departamento de Pediatria da Faculdade de Medicina da Universidade de São Paulo (FMUSP)

${ }^{4}$ Professor titular do Departamento de Pediatria da Universidade Federal da Bahia (UFBA)

${ }^{5}$ Doutor em Medicina pela Unifesp-EPM e professor associado do Departamento Materno-Infantil da Faculdade de Medicina do ABC (FMABC)

${ }^{6}$ Professor titular do Departamento de Pediatria da Universidade Federal

\section{ABSTRACT}

Objective: Review the available laboratory tests used to assist in the diagnosis of IgE-mediated and non-IgE-mediated food allergy.

Data sources: Papers in English and Portuguese published in PubMed and Embase, in the last ten years. Terms searched were "food allergy", "diagnose" and "laboratory", isolated and/or associated.

Data synthesis: The diagnostic approach to food allergy reactions includes a good medical history, laboratory studies, elimination diets and blinded food challenges. More recently, the use of a quantitative measurement of food-specific IgE antibodies has been shown to be more predictive of symptomatic IgEmediated food allergy. Food-specific IgE serum levels exceeding the diagnostic values indicate that the patient is greater than 95\% likely to experience an allergic reaction if he/she ingests the specific food. Such "decision point values" have been defined just for some foods and inconsistent results were obtained when allergy to the same food was studied in different centers. Food challenges, in particular the double-blind placebo-controlled food challenge (DBPCFC), represent the most reliable way to establish or rule out food hypersensitivity.

Conclusions: A number of recent developments are improving the predictive value of some laboratory tests for the diagnosis of food allergies. However, to date, no in-vitro or in-vivo test shows full correlation with clinical food allergy and the DBPCFC remains the gold standard for the definitive diagnosis of specific food allergies. There is an urgent need for new and fundamentally improved diagnostic approaches, which must be validated in patients with food allergy confirmed by a positive DBPCFC.

Key-words: food hypersensibitivity; immunoglobulin E; IgE-mediated hypergsensitivity; allergens, challenge

do Paraná (UFPR)

7Professor titular da Disciplina de Alergia, Imunologia Clínica e Reumatologia do Departamento de Pediatria da Unifesp-EPM

Endereço para correspondência:

Dirceu Solé

Rua Mirassol, 236, apto. 72 - Vila Mariana

CEP 04044-010 - São Paulo/SP

E-mail: dirceusole.dped@epm.br

Recebido em: 16/4/2007

Aprovado em: 5/6/2007 


\section{Introdução}

$\mathrm{Na}$ avaliação diagnóstica das reações adversas a alimentos, a história clínica tem papel fundamental. O seu valor depende muito da capacidade de recordação dos sintomas por parte dos pacientes e da habilidade do médico em diferenciar as manifestações causadas por hipersensibilidade alimentar daquelas relacionadas a outras condições. Isto nem sempre é tarefa fácil e tem propiciado muitos erros diagnósticos. Além disso, com base nas informações obtidas pela anamnese, a investigação laboratorial poderá ser implementada, lançando-se mão de exames complementares para confirmação e/ou elucidação diagnóstica.

Os mecanismos imunológicos, ou reações de hipersensibilidade, envolvidos na gênese das manifestações clínicas das doenças alérgicas são: tipo I ou mediado por IgE; tipo II ou de citotoxicidade; tipo III ou por imunecomplexos; tipo IV ou celular. Na alergia a alimentos, estes quatro tipos de reações de hipersensibilidade podem ocorrer e são responsabilizados por manifestações clínicas distintas. Entretanto, para simplificar o seu manejo, as reações alérgicas decorrentes de alimentos são classificadas em: mediadas por IgE (exemplos: urticária, angioedema, algumas manifestações gastrintestinais como edema e prurido de lábios, língua ou palato, vômitos e diarréia, sintomas respiratórios como prurido ocular e lacrimejamento, congestão nasal e broncoespasmo e reações sistêmicas como a anafilaxia com hipotensão e choque); mistas (mediadas por $\operatorname{IgE}$ e células); e não mediadas por IgE (reações citotóxicas e as por imunecomplexos - ambas com evidências limitadas, reações mediadas por linfócitos $\mathrm{T})^{(1)}$.

$\mathrm{Na}$ dependência dos mecanismos imunológicos envolvidos na gênese dos diferentes quadros de alergia alimentar, a abordagem laboratorial será distinta. Nesta revisão, será dado enfoque especial às reações mediadas por $\operatorname{IgE}$.

\section{Alergia alimentar mediada por IgE ou de tipo I}

Anticorpos IgE séricos específicos apresentam papel fundamental nas alergias alimentares IgE-mediadas. A IgE é produzida pela interação de vários tipos celulares após a exposição a antígenos, seja por via inalatória, cutânea ou parenteral. Uma vez acoplado às células apresentadoras de antígenos, o antígeno é processado e apresentado aos linfócitos $T$ auxiliares $\left(\mathrm{T}_{\mathrm{H}} 2\right)$, que, pela liberação de citocinas específicas, levam linfócitos $\mathrm{B}$ produtores de $\mathrm{IgE}$ à proliferação. As moléculas de IgE ligam-se a determinadas células, como mastócitos teciduais e basófilos, criando um estado de sensibilização. Exposições posteriores ao mesmo antígeno acarretam a ligação cruzada de IgE (mastócitos/basófilos e epítopos do alérgeno), aumento do influxo de cálcio intracelular e liberação de mediadores pré-formados (histamina, proteases) e neoformados (leucotrienos, prostaglandinas). Esses mediadores induzem às alterações fisiológicas e anatômicas que caracterizam os sintomas alérgicos.

A determinação da $\operatorname{IgE}$ sérica específica auxilia na identificação das alergias alimentares mediadas por IgE de tipo I ou anafiláticas. A pesquisa de IgE específica ao alimento suspeito pode ser realizada tanto in vivo pela realização dos testes cutâneos de hipersensibilidade imediata (TC), como in vitro pela dosagem da IgE específica no sangue (UniCAP ${ }^{\circledR}$ ). A detecção de IgE específica tem sido considerada como indicativo da sensibilização ao alimento, na maioria das vezes apenas orientando o alimento a ser utilizado no teste de provocação duplo-cego placebo controlado (DADCCP $)^{(2,3)}$.

A determinação de valores para TC (diâmetro médio da pápula) e de IgE específica pelo UniCAP System ${ }^{\circledR}$, capazes de detectar $95 \%$ dos casos de alergia alimentar mediados por $\operatorname{IgE}$ ao alimento suspeito, vem sendo descrita mais recentemente, na tentativa de dispensar o uso do teste considerado padrão-ouro no diagnóstico da alergia alimentar, o DADCCP ${ }^{(4,5)}$.

\section{Determinação de IgE específica}

In vivo - testes cutâneos de hipersensibilidade imediata

Os testes cutâneos têm sido utilizados há décadas para a medida da sensibilização aos alérgenos. São testes simples, rápidos e podem ser realizados no próprio consultório de médico treinado, mas requerem alguns cuidados em sua realização e interpretação. A utilização de extratos padronizados confere aos testes cutâneos valores preditivos positivos de, no máximo, $60 \%$, mas raramente são negativos em reações $\mathrm{IgE}$ mediadas (valor preditivo negativo de até $95 \%)^{(6,7)}$.

Os dois maiores problemas dos testes cutâneos no diagnóstico da alergia alimentar são a quantidade reduzida de extratos padronizados disponíveis para uso clínico e a instabilidade de muitos alérgenos alimentares, problemas que, certamente, poderão ser resolvidos com a futura introdução de alérgenos alimentares recombinantes.

Após a introdução epicutânea do alérgeno, pela utilização de puntor apropriado, aguarda-se 15 minutos para a leitura. São considerados positivos os resultados com formação de pápula de induração com pelo menos $3 \mathrm{~mm}$ de diâmetro médio, incluindo-se o controle positivo (solução de histamina) 
e na ausência de pápula com o controle negativo (excipiente da solução). Não há restrição de idade para a realização do testes cutâneos, entretanto, deve-se ter em mente que crianças menores de seis meses de idade podem não ter sido expostas a vários alimentos, com possibilidade de testes positivos apenas para aqueles a que foi sabidamente exposta.

A utilização de alérgenos in natura aplicados na pele do paciente pode ser útil naqueles com história clara de relação entre determinado alérgeno e sintomas e quando não se dispõe de extratos padronizados. Esta variação dos testes cutâneos, introduzida por Dreborg e Foucard em 1983 para frutas e vegetais frescos, recebeu a denominação de "prick to prick" e, à semelhança do teste cutâneo por puntura, deve ser acompanhado pelos controles positivo e negativo, para sua interpretação ${ }^{(8)}$. Para alguns autores, o uso do prick to prick para alimentos pode ser superior ao uso dos extratos comerciais ${ }^{(9,10)}$.

A realização dos testes cutâneos sofre algumas restrições, cabendo ao médico especialista avaliar cada caso. Entre as restrições destacam-se:

- Embora muito seguro, o teste cutâneo pode desencadear reações sistêmicas - segundo Valyasevi, em 33/100.000 testes cutâneos realizados ${ }^{(11)}$. Cuidados especiais devem ser tomados em pacientes com história prévia de anafilaxia, entre os com asma ou quando são utilizados extratos não comerciais e não padronizados;

- Uso prévio de anti-histamínicos ou antidepressivos, recomendando-se sua suspensão pelo menos cinco dias antes da realização do teste cutâneo;

- Pacientes com dermografismo evidente, o que poderia gerar resultados falso-positivos;

- Pacientes com lesões cutâneas extensas, distúrbios de coagulação ou em uso de beta-bloqueadores.

$\mathrm{Na}$ tentativa de definir a acurácia dos testes cutâneos no diagnóstico da alergia alimentar mediada por IgE, Hill et a ${ }^{(12)}$ determinaram os valores médios de corte para o diâmetro médio das pápulas ao teste cutâneo com leite de vaca, clara de ovo e amendoim, acima dos quais o valor preditivo positivo para o diagnóstico de alergia alimentar fosse $100 \%$. Analisaram 467 crianças com média de idade de três anos, que realizaram 555 provocações orais abertas, e definiram pápulas com diâmetro maior ou igual a $8 \mathrm{~mm}$ para o leite de vaca e amendoim e $7 \mathrm{~mm}$ para ovo, em crianças acima de dois anos. Para crianças menores de dois anos, os valores dos diâmetros médios das pápulas do teste cutâneo que permitiriam o diagnóstico de alergia alimentar seriam $6 \mathrm{~mm}$ para o leite, $5 \mathrm{~mm}$ para o ovo e $4 \mathrm{~mm}$ para o amendoim.
Outra utilidade do teste cutâneo seria o seu uso na previsão da tolerância ao alérgeno relacionado à alergia alimentar. Vanto $e$ e $a^{(4)}$ realizaram estudo prospectivo em 163 crianças com alergia ao leite de vaca. Aos quatro anos, avaliaram se a tolerância ao leite de vaca poderia ser prevista pelo teste cutâneo ou medida da IgE sérica específica. Os autores demonstraram que pápulas menores do que $5 \mathrm{~mm}$ e valores de IgE específica menores de $2 \mathrm{kU} / \mathrm{L}$ para leite de vaca identificavam, respectivamente, 83 e $82 \%$ das crianças que se tornaram tolerantes aos quatro anos de idade.

\section{In vitro - IgE sérica específica}

As IgEs humanas são imunoglobulinas com peso molecular aproximado de $190.000 \mathrm{Da}$ que circulam no sangue periférico como monômeros. Sua concentração no sangue periférico é dependente da idade, constitui aproximadamente $0,0005 \%$ do total das imunoglobulinas séricas no adulto e requer métodos específicos e sensíveis o suficiente para detectá-las ${ }^{(13)}$. Seus valores são representados por unidades internacionais de quilo por litro (kIU/L). Ainda que os níveis de IgE total sejam baixos, podem ser detectados valores aumentados de IgE específica para determinado alérgeno ${ }^{(13)}$.

O primeiro método descrito para a detecção de IgE específica foi o Phadebas Radioalergosorbente Teste, em 1967 (RAST, Pharmacia, Uppsala, Suécia). O método consistia na mensuração da ligação da IgE de soro de pacientes com determinados antígenos depositados em discos de celulose, por meio de marcadores radioativos e imunorradiometria ${ }^{(13)}$.

Os modelos que se seguiram, denominados de "segunda geração", foram baseados no mesmo método de análise quantitativa de ligação do antígeno com anticorpo ( $\operatorname{IgE}$ ), mas com maior sensibilidade e especificidade, por utilizarem extratos alergênicos de melhor qualidade e com maior quantidade de alérgenos (poli e monoclonais) ${ }^{(14)}$.

$\mathrm{O}$ método mais popular para determinar a IgE específica é o Sistema ImmunoCAP ${ }^{\circledR}$, apesar de outros recursos menos onerosos, simples e também sensíveis, como o ELISA, poderem ser utilizados. Vale um destaque para os microarrays, sistema de chips no qual são expressas proteínas heterólogas que detectam a ligação da IgE específica por meio de imagens fluorescentes, necessitando de mínimas quantidades de sangue do paciente.

\section{Níveis de IgE sérica específica como parâmetro diagnóstico}

Devido à estreita associação entre a IgE específica e as reações imunológicas a alimentos, tenta-se estabelecer parâmetros de 
relação entre seus níveis séricos e a chance de reações clínicas como um instrumento preciso para diagnóstico.

O padrão-ouro para o diagnóstico das alergias alimentares é o teste de provocação oral, duplo-cego e controlado por placebo. A limitação de sua aplicabilidade na prática clínica diária impõe a necessidade de estabelecer outros métodos diagnósticos que facilitem ao médico a decisão de submeter ou não o paciente ao teste. Sampson et al utilizaram a mensuração dos níveis de IgE específica nos pacientes que apresentavam reações quando submetidos ao teste de provocação com determinado alimento. A análise estatística destes dados permitiu que fossem estabelecidos valores mínimos de $\operatorname{IgE}$, a partir dos quais $90 \%$ dos pacientes cursavam com reações clínicas durante o teste. Os valores de corte ( $7 \mathrm{kIU} / \mathrm{L}$ para ovo, $15 \mathrm{kIU} / \mathrm{L}$ para leite de vaca e $14 \mathrm{kIU} / \mathrm{L}$ para amendoim), no entanto, variam de acordo com a população estudada e não podem ser tomados como parâmetros absolutos, tendo em vista diferenças regionais e hábitos alimentares particulares ${ }^{(15,16)}$.

Outros grupos de estudos correlacionaram os níveis de $\operatorname{IgE}$ específica e a chance de reatividade clínica por meio de métodos diferentes. Perry et a ${ }^{(17)}$ avaliaram pacientes alérgicos a leite de vaca, ovo e amendoim e verificaram que cerca de $50 \%$ deles apresentavam testes orais positivos quando seus níveis de $\operatorname{IgE}$ específica eram maiores ou iguais a $2 \mathrm{kIU} / \mathrm{L}$. Boyano-Martinez ${ }^{(18)}$, em ensaio prospectivo, observou que níveis maiores que $0,35 \mathrm{kIU} / \mathrm{L}$ de $\mathrm{IgE}$ específica para ovo eram preditivos de reatividade clínica em $94 \%$ dos casos de história sugestiva.

Ainda não existem parâmetros estabelecidos de valores séricos de IgE específica em nossa população que possam auxiliar no diagnóstico e/ou decisão para realização do teste de provocação oral.

\section{IgE sérica específica e reatividade cruzada}

Ainda que não pertençam à mesma classificação taxonômica, determinadas proteínas apresentam seqüências idênticas de aminoácidos. É o caso do pólen ou do látex com algumas frutas e vegetais. Outras vezes, a similaridade entre as proteínas ocorre intra e interespécies, como o leite e a carne bovinos e as leguminosas, respectivamente. Esta homologia explica a importância da IgE nas reações cruzadas: a sensibilização a uma das proteínas pode levar a reações alérgicas quando houver exposição a proteínas semelhantes, não necessariamente do mesmo alérgeno $(\text { Tabela } 1)^{(19)}$.

Uma seqüência idêntica de aminoácidos isolada, no entanto, não é fator único para o aparecimento de reação alérgica cruzada. A afinidade desta seqüência à $\operatorname{IgE}$, sua estrutura espacial (linear $\mathrm{x}$ tridimensional) e o grau de homogeneidade (de $25 \%$ a mais de $70 \%$ de similaridade) são fatores determinantes para que o reconhecimento das proteínas pelo sistema imunológico se transforme em reação clínica ${ }^{(20,21)}$.

\section{IgE sérica específica versus teste cutâneo de hipersensibilidade alérgica}

Em relação às alergias alimentares, tanto a mensuração in vitro como in vivo são consideradas equivalentemente aceitáveis. A melhor avaliação do paciente é obtida quando ambos os testes são realizados concomitantemente. A sensibilidade dos dois testes na alergia alimentar é semelhante ${ }^{(12)}$.

O teste cutâneo é um método rápido, fácil e seguro para avaliar a sensibilização a um alérgeno, largamente utilizado com extratos comerciais e alimentos frescos e, mais raramente, com antígenos purificados. A liberação de histamina pelos mastócitos cutâneos ativados leva à formação de pápula e eritema locais, indicando a presença de $\operatorname{IgE}$ específica. Alguns autores, de modo semelhante ao que foi descrito nos métodos in vitro, tentaram estabelecer valores limites no diâmetro da pápula, a partir dos quais o paciente teria $100 \%$ de chance de apresentar reações clínicas. Sporik et al ${ }^{(22)}$ encontraram pápulas de $8 \mathrm{~mm}$ de diâmetro para leite de vaca, $7 \mathrm{~mm}$ para ovo e $8 \mathrm{~mm}$ para amendoim, acima dos quais os pacientes teriam 100\% de chance de apresentar reações quando submetidas ao teste de provocação oral. No entanto, as mesmas observações referidas aos estudos de IgE sérica quanto à limitação dos valores para a população estudada devem ser admitidas. Primeiro, porque os investigadores utilizam diferentes critérios para aplicação/método do teste. Segundo, porque a população dos estudos difere muito em relação à magnitude e freqüência de exposição aos alérgenos. Terceiro, a interpretação dos métodos de detecção da IgE depende do parâmetro estabelecido como basal, que varia muito entre os estudos clínicos in vivo.

Tabela 1 - Exemplos de alérgenos com similaridade de seqüências protéicas e conseqüente risco de reações cruzadas

\begin{tabular}{ll}
\hline Alérgeno & Risco de reação cruzada com \\
\hline Amendoim & Ervilha, lentilha, feijão \\
Nozes & Castanha-do-pará, avelã \\
Salmão & Peixe-espada, linguado \\
Camarão & Caranguejo, lagosta \\
Trigo & Centeio, cevada \\
Leite de vaca & Carne (bovina), leite de cabra \\
Pólen & Maçã, pêssego, melão \\
Látex & Kiwi, banana, abacate \\
\hline
\end{tabular}




\section{Valores de IgE como parâmetro no acompanhamento clínico}

Pacientes com níveis elevados de IgE específica parecem ter maior probabilidade de apresentar reação clínica, comparados aos indivíduos com níveis mais baixos. Em vista disso, o monitoramento semestral/anual dos níveis de $\operatorname{IgE}$ sérica seria um importante instrumento de controle clínico e decisão para o melhor momento de testar a tolerância oral (perda da sensibilidade). A diminuição contínua dos níveis séricos de IgE específica, associada à ausência de reações clínicas e à idade do paciente (cerca de $85 \%$ das crianças remitem sua hipersensibilidade aos alimentos por volta dos três anos de idade) permitiriam ao médico indicar o teste de provocação oral e possível reintrodução do alimento à dieta do paciente ${ }^{(23)}$.

\section{Outros marcadores sorológicos}

\section{Quantificação da liberação de histamina por basófilos}

Ensaios da liberação de histamina por basófilos periféricos e por mastócitos intestinais para avaliar a alergia alimentar mediada pela IgE são geralmente utilizados apenas em pesquisa. Estudo que comparou testes da liberação de histamina por basófilos e por mastócitos intestinais com os testes cutâneos, IgE sérica específica, e provocação alimentar em crianças com suspeita de alergia alimentar revelou que a medida da liberação de histamina por basófilos se correlacionou melhor com os resultados da IgE sérica específica ${ }^{(24)}$. Entretanto, outro estudo que comparou ensaios de liberação de histamina por basófilos induzida por alimentos, teste cutâneo e provocação oral duplo-cega controlada por placebo demonstrou que a liberação de histamina por basófilos não apresentava maior valor preditivo de sensibilidade clínica do que o teste cutâneo ${ }^{(25)}$.

O monitoramento da liberação "espontânea" de histamina e da geração de "fator liberador de histamina" demonstrou ser altamente preditivo das alergias alimentares mediadas pela $\operatorname{Ig} \mathrm{E}$ em pacientes que continuam ingerindo o alérgeno envolvido, mas não provou ser prático do ponto de vista clínico ${ }^{(26)}$.

\section{Quantificação da expressão de CD63 em basófilos}

A ativação de basófilos IgE-dependentes induzida por alérgenos ocasiona a expressão do marcador de membrana CD63. Assim, uma avaliação que tem chamado a atenção dos pesquisadores é a quantificação da expressão de CD63 em basófilos, após estimulação com antígeno in vitro. Estudo que investigou pacientes com alergia à cenoura, aipo e avelã associada à alergia a pólens constatou sensibilidade discretamente superior da quantificação da expressão de CD63 em basófilos, quando comparada à quantificação de $\operatorname{IgE}$ alérgeno específica. Houve ainda boa correlação entre a reatividade IgE e o número de basófilos CD63 positivos, para todos os alérgenos testados ${ }^{(27)}$.

É possível que esse tipo de avaliação venha a ser, em alguns casos, um instrumento adicional para o diagnóstico in vitro. Contudo, esses achados iniciais precisam ser validados por outros estudos clínicos antes que seu emprego rotineiro possa ser recomendado.

\section{Desencadeamento oral (aberto e fechado)}

Os testes de provocação oral são considerados os únicos métodos fidedignos para estabelecer o diagnóstico de alergia alimentar. Consistem na oferta de alimentos e/ou placebo em doses crescentes e intervalos regulares, sob supervisão médica, com concomitante monitoramento de possíveis reações clínicas ${ }^{(28)}$.

De acordo com o conhecimento do paciente (ou de sua família) e do médico quanto à natureza da substância ingerida (alimento ou placebo mascarado), os testes são classificados em aberto (paciente e médico cientes), simples-cego (apenas o médico sabe o que está sendo administrado) ou duplo-cego e controlado por placebo, no qual nenhuma das partes tem conhecimento do preparado a ser testado pelo paciente. Esta última condição, apesar de estabelecida como padrão-ouro para o diagnóstico das alergias alimentares, tem sua utilização limitada na prática clínica diária pelos custos envolvidos, tempo necessário para sua realização e chance de reações graves ${ }^{(28)}$.

Na vigência de reações graves anteriores, o procedimento deve ser realizado em ambiente hospitalar, com recursos de emergência disponíveis.

As situações em que a necessidade dos testes de provocação oral se impõe são:

1) casos em que diversos alimentos são considerados suspeitos, seus testes específicos para $\operatorname{IgE}$ são positivos e a restrição de todos esses alimentos da dieta é imposta: o teste oral para cada um dos alimentos seria indicado para a reintrodução à dieta dos alimentos que não provocaram reação;

2) reações do tipo anafiláticas, cujo alimento altamente suspeito não apresenta positividade no teste de $\operatorname{IgE}$ específica (o teste de provocação deverá ser realizado em ambiente hospitalar, com material de emergência disponível);

3) necessidade de estabelecer a relação causa $\mathrm{x}$ efeito entre o alimento e os sintomas, mesmo que haja melhora do quadro após sua restrição da dieta;

4) alergias parcialmente ou não mediadas por $\operatorname{IgE}$, quando os testes laboratoriais são de pequeno auxílio diagnóstico ${ }^{(28)}$. 
Além disso, os testes orais fazem parte do acompanhamento da história natural da alergia e podem ser negativos mesmo quando os testes laboratoriais apontam para valores de $\operatorname{Ig} \mathrm{E}$ específica maiores do que o limite de normalidade.

A história de anafilaxia grave com alimento isolado e presença de anticorpo IgE específico para o alimento causal contraindica a realização do desencadeamento.

Uma vez avaliada a necessidade do teste, deve-se ponderar os riscos e benefícios com o paciente e/ou sua família. Se houver a mais remota possibilidade de reação aguda e/ou grave, o teste deverá ser realizado na presença do médico e sob condições que possibilitem socorro imediato (adrenalina, anti-histamínicos, corticosteróides, broncodilatadores inalatórios, carvão ativado, expansores de volume e material para intubação traqueal). Pacientes considerados de alto risco (reação grave com positividade de IgE para o alimento suspeito, asmáticos) devem ser desencadeados em ambiente hospitalar, com acesso intravenoso prévio.

Os pacientes precisam estar em restrição do alimento suspeito por pelo menos duas semanas, os anti-histamínicos devem ser suspensos de acordo com sua meia vida e as medicações para asma, reduzidas ao limite mínimo para evitar sintomas.

Como mencionado anteriormente, os testes são classificados de acordo com o conhecimento da substância a ser ingerida pelas partes envolvidas: paciente (e/ou sua família) e o médico observador. Existem diversos protocolos sugerindo doses e intervalos de tempo. Um exemplo prático, para reações mediadas por IgE, o protocolo baseia-se na oferta de 8 a $10 \mathrm{~g}$ do alimento desidratado ou $100 \mathrm{~mL}$ na forma líquida, a cada 10 a 15 minutos, por cerca de 90 minutos. Outros autores iniciam o teste com doses mais baixas, que são dobradas sucessivamente.

Alguns autores preconizam o teste labial no início do procedimento, aplicando o alimento (ou placebo) no lábio inferior do paciente e prosseguindo com a realização do teste se não houver qualquer reação local ou sistêmica após alguns minutos.

\section{Aberto}

É utilizado principalmente para retirar conceitos subjetivos do paciente quando a história clínica e os exames laboratoriais descartam a possibilidade de alergia. $\mathrm{O}$ procedimento não requer maiores preparos do alimento, que pode ser trazido pelo paciente ao consultório. Quando há suspeitas no resultado, deve-se programar o teste duplo-cego, controlado por placebo. O teste aberto também é proposto como finalização do duplo-cego (negativo) como forma de eliminação de qualquer suspeita àquele alimento ${ }^{(28)}$.

Em crianças menores de um ano de idade, o teste aberto tem fidedignidade semelhante à do teste duplo-cego ${ }^{(29)}$.

Pela facilidade do procedimento, em relação às formas que serão abordadas a seguir, o teste aberto acaba sendo o mais utilizado na prática clínica diária dos especialistas. É importante ressaltar, no entanto, que seu valor diagnóstico não é igual aos demais.

\section{Simples ou uni-cego}

Neste desencadeamento, apenas o médico observador tem conhecimento da substância a ser ingerida. O método utilizado, bem como os preparados a serem ingeridos, é semelhante ao descrito a seguir.

\section{Duplo-cego controlado por placebo}

Nenhuma das partes envolvidas deve ter conhecimento da substância ingerida, que deverá estar devidamente rotulada como substância "A" ou "B", conhecida apenas por um terceiro profissional (nutricionista ou enfermeira, por exemplo), responsável pela randomização ${ }^{(30)}$.

O teste deve ser realizado em dias separados, um para o alimento, outro para o placebo. Em casos de reações mediadas por $\mathrm{IgE}$, os dois testes podem ser ministrados no mesmo dia, desde que haja um intervalo de quatro horas entre eles. O preparo envolve um mascaramento do alimento, sua cor, sabor e odor. Esse resultado pode decorrer da mistura com outro alimento ou por sua liofilização, oferecido por cápsulas de gelatina ${ }^{(31)}$.

Alguns veículos utilizados para mascarar as características do alimento estão na Tabela 2.

Tabela 2 - Sugestões de alimentos mais alergênicos para teste de provocação oral

\begin{tabular}{|c|c|c|c|}
\hline Alimento & Opção para teste & Opção de placebo & Veículos \\
\hline Leite & Leite em pó & Farinha de trigo, aveia & $\begin{array}{l}\text { Fórmulas de arroz ou soja, pudins } \\
\text { (sem leite) }\end{array}$ \\
\hline Ovo & Clara desidratada & Farinha de milho ou trigo, aveia & Purê de batatas, pudins \\
\hline Trigo & Farinha de trigo & Farinhas de arroz, aveia ou cevada & Pudins, sucos de frutas, milk shakes \\
\hline Soja & Fórmulas de soja em pó & $\begin{array}{l}\text { Farinhas de arroz, milho, fórmulas } \\
\text { hidrolisadas }\end{array}$ & Pudins, hidrolisados \\
\hline Amendoim & $\begin{array}{l}\text { Farelo de amendoim } \\
\text { (liquidificador) }\end{array}$ & Farinhas de grãos & Chocolate, sorvete \\
\hline
\end{tabular}




\section{Alergia alimentar não-IgE mediada}

Sob esta denominação estão reunidas todas as manifestações de hipersensibilidade em que os anticorpos IgE não têm participação. Estes quadros podem ser deflagrados por anticorpos séricos específicos a antígenos alimentares e, algumas vezes, por linfócitos T. A avaliação da imunidade celular frente a antígenos alimentares tem sido restrita a protocolos de investigação e ainda necessita de padronização. À semelhança das alergias alimentares mediadas por IgE, o DADCCP é o padrão-ouro na confirmação diagnóstica desses quadros de alergia alimentar.

\section{Quantificação de anticorpos IgG e IgG4 séricos específicos}

A produção de anticorpos IgG e IgG4 específicos constitui resposta fisiológica à ingestão de alimentos, sem que implique qualquer manifestação clínica de hipersensibilidade alimentar ${ }^{(32,33)}$. Apesar disso, painéis de anticorpos IgG ou IgG4 específicos para antígenos alimentares têm sido proclamados por alguns como instrumentos diagnósticos na alergia alimentar.

Vários laboratórios americanos e europeus oferecem esses testes a médicos e, até mesmo, diretamente aos pacientes, afirmando serem capazes de identificar "intolerâncias" e alergias alimentares que ocasionam ou contribuem para fadiga crônica, obstrução nasal, problemas sinusais, cefaléias, hiperatividade, síndrome do intestino irritável, artrite e quase qualquer sintoma somático ou mental ${ }^{(34)}$.

Contudo, as evidências disponíveis não dão suporte à eficácia diagnóstica da dosagem de IgG específica em nenhuma doença em particular além da hemossiderose

Quadro 1 - Principais aspectos a serem investigados antes do teste de provocação oral

1. Alimento(s) suspeito(s)

2. Tempo entre a ingestão do alimento e o aparecimento dos sintomas

3. A menor quantidade do alimento suspeito ingerido, capaz de deflagrar reações

4. Freqüência e reprodutibilidade das reações

5. Fatores associados à reação adversa (álcool, exercícios)

6. Época da última reação

7. Descrição de sinais (rinite, urticária, eczema, rinorréia, tosse, crise de asma, hipersecreção, vômitos, diarréia e cólica) pulmonar (Síndrome de Heiner). Essa síndrome rara é mais freqüentemente associada à hipersensibilidade ao leite de vaca não mediada pela $\mathrm{IgE}$, embora haja também relatos de reatividade ao ovo e à carne de porco. Tem sido descrita como relacionada a níveis extremamente elevados de IgG específica para antígenos alimentares mediante emprego de ensaios de precipitinas ${ }^{(35)}$.

\section{Quantificação de complexos antígeno-anticorpo}

A reação de hipersensibilidade do tipo III (mediada por complexo antígeno-anticorpo) é implicada na gênese de quadros intestinais, especialmente colite, associados à ingestão de alimentos. Contudo, os complexos antígeno alimentar-anticorpo podem ser encontrados circulantes no soro de indivíduos com suspeita de hipersensibilidade alimentar ou de indivíduos normais. Nesse sentido, já se demonstrou, por exemplo, que complexos formados pela interação de anticorpos $\operatorname{Ig} G, \operatorname{Ig} A$ ou $\operatorname{Ig} M$ contra a beta lactoglobulina são detectados cerca de uma a três horas após a ingestão de leite, em crianças e adultos normais ${ }^{(36)}$. De maneira semelhante, embora complexos IgE-antígeno alimentar estejam mais comumente presentes em pacientes com alergia alimentar, existe pouco suporte para se admitir que a doença seja mediada por esses complexos ${ }^{(37)}$.

Assim, não existem evidências do valor da quantificação de complexos alimentares antígeno-anticorpo, no diagnóstico da hipersensibilidade alimentar.

\section{Alergia alimentar mediada por mecanismo misto}

Nesses quadros clínicos, a avaliação compreende as realizadas para as reações IgE mediadas e não-IgE mediadas.

\section{Outros procedimentos}

Em situações especiais, podem ser necessários testes adicionais para elucidação diagnóstica e/ou de complicações associadas. Essa avaliação, em geral, requer a participação de outros especialistas além do alergologista; desse modo, a investigação complementar deve ser direcionada às manifestações clínicas. Assim, nesta fase, podem ser necessários ainda: teste de tolerância à lactose, testes de absorção intestinal, pHmetria esofágica (um ou dois canais), exame contrastado do trato gastrintestinal, endoscopia do trato gastrintestinal, biópsia de intestino, entre outros, sempre por indicação do gastroenterologista pediátrico. 


\section{Considerações finais}

O número crescente de aquisições tem melhorado o valor preditivo de alguns testes laboratoriais empregados no diagnóstico de alergias alimentares. Entretanto, até hoje não há teste in vitro ou in vivo que mostre correlação completa com a clínica da alergia alimentar. O desen- cadeamento com alimento duplo-cego controlado por placebo continua sendo o padrão-ouro no diagnóstico definitivo de alergia alimentar específica. São necessárias, urgentemente, novas abordagens diagnósticas, que sejam válidas em pacientes com alergia alimentar confirmada por desencadeamento com alimento duplo-cego controlado por placebo positivo.

\section{Referências bibliográficas}

1. Nowak-Wegrzyn A, Sampson H. Adverse reactions to foods. Med Clin North Am 2006;90:97-127.

2. Baral VR, Hourihane JO. Food allergy in children. Postgrad Med J 2005;81:693-701.

3. Beyer K, Teuber SS. Food allergy diagnostics: scientific and unproven procedures. Curr Opin Allergy Clin Immunol 2005;5:261-6.

4. Vanto T, Helppilä S, Juntunen-Backman K, Kalimo K, Klemola T, Korpela R et al. Prediction of the development of tolerance to milk in children with cow's milk hypersensitivity. J Pediatr 2004;144:218-22.

5. Verstege A, Mehl A, Rolinck-Werninghaus C, Staden U, Nocon M, Beyer K et al. The predictive value of the skin prick test weal size for the outcome of oral food challenges. Clin Exp Allergy 2005;35:1220-6.

6. Crespo JF, James JM, Rodriguez J. Diagnosis and therapy of food allergy. Mol Nutr Food Res 2004:48:347-55.

7. Sampson HA. Food allergy. JAMA 1997;278:1888-94.

8. Dreborg S, Foucard T. Allergy to apple, carrot and potato in children with birch pollen allergy. Allergy 1983;38:167-72.

9. Ortolani C, Ispano M, Pastorello EA, Ansaloni R, Magri GC. Comparison of results of skin prick tests (with fresh foods and commercial food extracts) and RAST in 100 patients with oral allergy syndrome. J Allergy Clin Immunol 1989;83:683-90.

10. Rance F, Juchet A, Bremont F, Dutau G. Correlations between skin prick tests using commercial extracts and fresh foods, specific $\lg E$, and food challenges. Allergy 1997;52:1031-5.

11. Valyasevi MA, Maddox DE, Li JT. Systemic reactions to allergy skin tests. Ann Allergy Asthma Immunol 1999;83:132-6.

12. Hill DJ, Heine RG, Hosking CS. The diagnostic value of skin prick testing in children with food allergy. Pediatr Allergy Immunol 2004;15:435-41.

13. Ishizaka K, Ishizaka T. Identification of gamma-E-antibodies as a carrier of reaginic activity. J Immunol. 1967; 99:1187-98.

14. Wide $L$, Bennich $H$, Johansson SG. Diagnosis of allergy by an in vitro test for allergen antibodies. Lancet 1967;2:1105-7.

15. Sampson HA. Utility of food-specific IgE concentrations in predicting symptomatic food allergy. J Allergy Clin Immunol 2001;107:891-6.

16. Sampson HA. Improving in-vitro tests for the diagnosis of food hypersensitivity. Curr Opin Allergy Clin Immunol. 2002;2:257-61.

17. Perry TT, Matsui EC, Conover-Walker M, Wood RA. The relationship of allergen-specific IgE levels and oral food challenge outcomes. J Allergy Clin Immunol 2004;114:144-9.

18. Boyano Martínez T, García-Ara C, Díaz-Pena JM, Muñoz FM, García Sánchez G, Esteban MM. Validity of specific IgE antibodies in children with egg allergy. Clin Exp Allergy 2001; 31:1464-9.

19. Sicherer SH. Clinical implications of cross-reactive food allergens. J Allergy Clin Immunol 2001;108:881-90.

20. Aalberse RC. Structural biology of allergens. J Allergy Clin Immunol 2000;106:228-38.
21. Sánchez-Monge R, Salcedo G. Analytical methodology for assessment of food allergens: opportunities and challenges. Biotechnol Adv 2005;23:415-22.

22. Sporik R, Hill DJ, Hosking CS. Specificity of allergen skin testing in predicting positive open food challenges to milk, egg, and peanut in children. Clin Exp Allergy 2000;30:1540-6.

23. Skolnick HS, Conover-Walker MK, Koerner CB. The natural history of peanut allergy. J Allergy Clin Immunol 2001;107:367-74.

24. Nolte H, Schiotz PO, Kruse A, Stahl Skov P. Comparison of intestinal mast cell and basophil histamine release in children with food allergic reactions. Allergy 1989;44:554-65.

25. Sampson HA. In vitro diagnosis and mediator assays for food allergies. Allergy Proc 1993;14:259-61.

26. Sampson HA, Broadbent KR, Bernhisel-Broadbent J. Spontaneous release of histamine from basophils and histamine-releasing factor in patients with atopic dermatitis and food hypersensitivity. N Engl J Med 1989;321:228-32.

27. Erdmann SM, Heussen N, Moll-Slodowy S, Merk HF, Sachs B. CD63 expression on basophils as a tool for the diagnosis of pollen-associated food allergy: sensitivity and specificity. Clin Exp Allergy 2003;33:607-14.

28. Sicherer SH. Food allergy: when and how to perform oral food challenges. Pediatr Allergy Immunol 1999;10:226-34.

29. Rance F, Dutau G. Labial food challenge in children with food allergy. Pediatr Allergy Immunol 1997;8:41-4.

30. Niggemann B, Sielaff B, Beyer K, Binder C, Wahn U. Outcome of double-blind, placebo-controlled food challenge tests in 107 children with atopic dermatitis. Clin Exp Allergy 1999;29:91-6.

31. Huijbers GB, Colen AA, Jansen JJ, Kardinaal AF, Vlieg-Boerstra BJ, Martens BP. Masking foods for food challenge: practical aspects of masking foods for a doubleblind, placebo-controlled food challenge. J Am Diet Assoc 1994;94:645-9.

32. Morgan JE, Daul CB, Lehrer SB. The relationship among shrimp-specific IgG subclass antibodies and immediate adverse reactions to shrimp challenge. $J$ Allergy Clin Immunol 1990;86:387-92.

33. Szabo I, Eigenmann PA. Allergenicity of major cow's milk and peanut proteins determined by IgE and IgG immunoblotting. Allergy 2000;55:42-9.

34. Beyer K, Teuber SS. Food allergy diagnostics: scientific and unproven procedures. Curr Opin Allergy Clin Immunol 2005;5:261-6.

35. Teuber SS, Porch-Curren C. Unproved diagnostic and therapeutic approaches to food allergy and intolerance. Curr Opin Allergy Clin Immunol 2003;3:217-21.

36. Paganelli R, Levinsky RJ, Brostoff J, Wraith DG. Immune complexes containing food proteins in normal and atopic patients after oral challenge and effect of sodium cromoglycate on antigen absorption Lancet 1979;1:1270-2.

37. Paganelli R, Quinti I, D’Offizi G, Papetti C, Carini C, Aiuti F. Immune complexes in food allergy: a critical reappraisal 1987;59:157-61. 